\title{
Additive Manufacturing of Polyurethane Materials
}

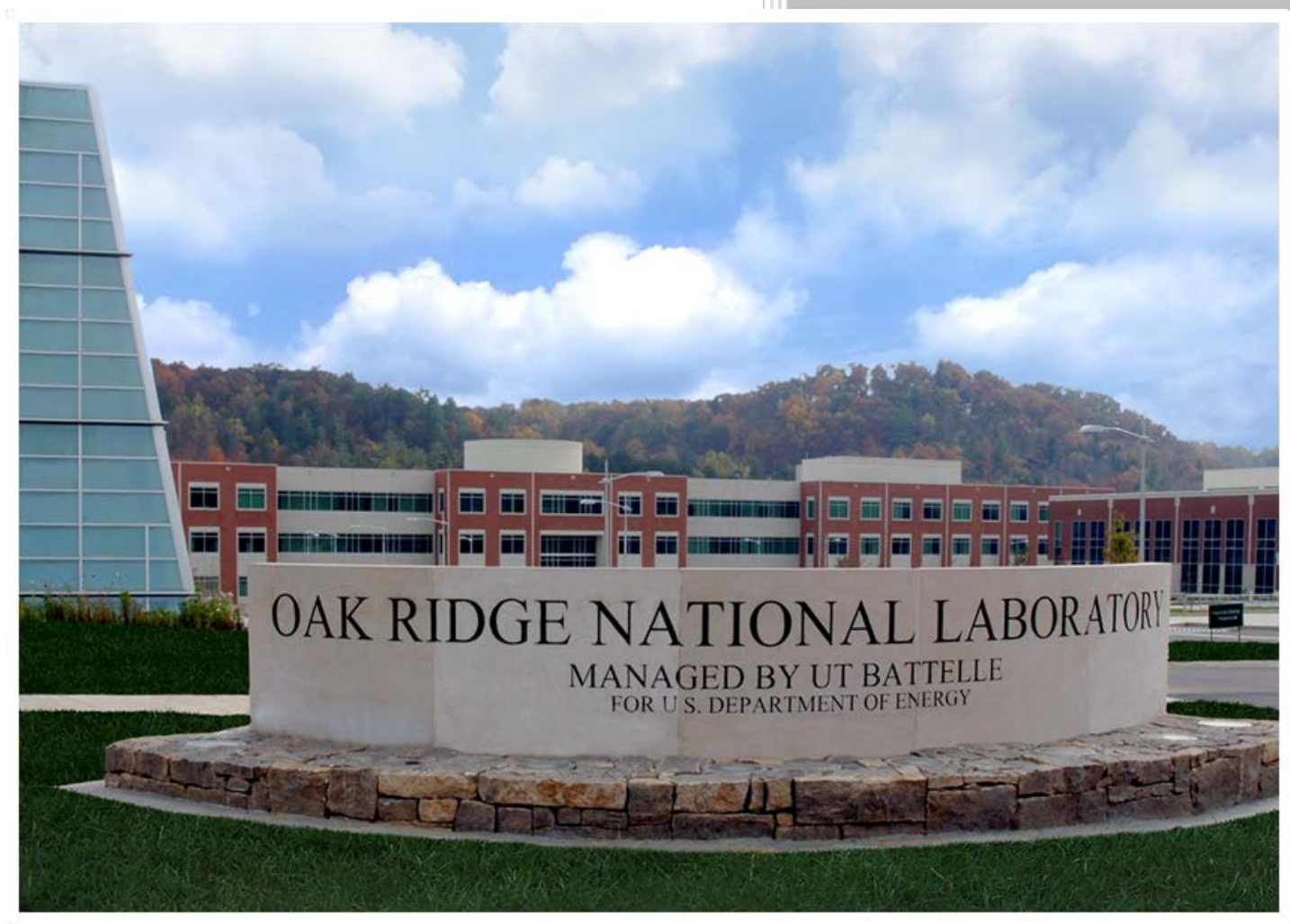

Vlastimil Kunc

August 10, 2017

CRADA FINAL REPORT NFE-16-0654

Approved for Public Release. Distribution is Unlimited. 


\title{
DOCUMENT AVAILABILITY
}

Reports produced after January 1, 1996, are generally available free via US Department of Energy (DOE) SciTech Connect.

Website http://www.osti.gov/scitech/

Reports produced before January 1, 1996, may be purchased by members of the public from the following source:

\author{
National Technical Information Service \\ 5285 Port Royal Road \\ Springfield, VA 22161 \\ Telephone 703-605-6000 (1-800-553-6847) \\ TDD 703-487-4639 \\ Fax 703-605-6900 \\ E-mail info@ntis.gov \\ Website http://www.ntis.gov/help/ordermethods.aspx
}

Reports are available to DOE employees, DOE contractors, Energy Technology Data Exchange representatives, and International Nuclear Information System representatives from the following source:

Office of Scientific and Technical Information

PO Box 62

Oak Ridge, TN 37831

Telephone 865-576-8401

Fax 865-576-5728

E-mail reports@osti.gov

Website http://www.osti.gov/contact.html

This report was prepared as an account of work sponsored by an agency of the United States Government. Neither the United States Government nor any agency thereof, nor any of their employees, makes any warranty, express or implied, or assumes any legal liability or responsibility for the accuracy, completeness, or usefulness of any information, apparatus, product, or process disclosed, or represents that its use would not infringe privately owned rights. Reference herein to any specific commercial product, process, or service by trade name, trademark, manufacturer, or otherwise, does not necessarily constitute or imply its endorsement, recommendation, or favoring by the United States Government or any agency thereof. The views and opinions of authors expressed herein do not necessarily state or reflect those of the United States Government or any agency thereof. 
ORNL/TM-2017/394

CRADA/NFE-16-06054

Materials Science and Technology Division Advanced Manufacturing Office

\title{
Additive Manufacturing of Polyurethane Materials
}

\author{
Authors \\ Vlastimil Kunc (ORNL) \\ John Lindahl (ORNL) \\ Robert Minneci \\ Alek Pyzik \\ Craig Gorin \\ Sharon Allen \\ Keith Wilson \\ Kevin Howard
}

Date Published:

August 10, 2017

\author{
Prepared by \\ OAK RIDGE NATIONAL LABORATORY \\ Oak Ridge, Tennessee 37831-6283 \\ managed by \\ UT-BATTELLE, LLC \\ for the \\ US DEPARTMENT OF ENERGY \\ under contract DE-AC05-00OR22725
}

Approved For Public Release 


\section{CONTENTS}

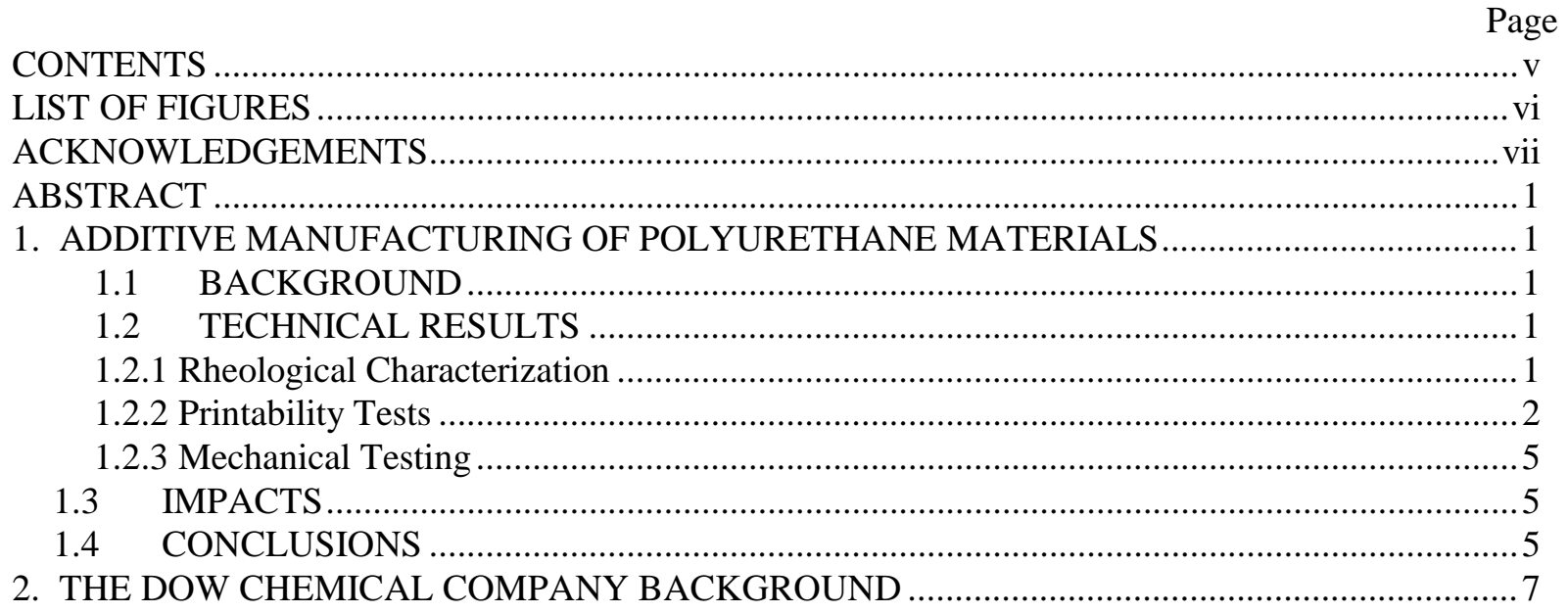




\section{LIST OF FIGURES}

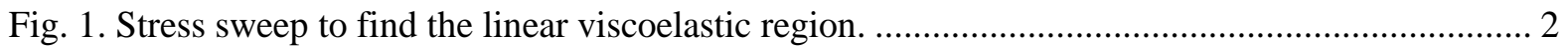

Fig. 2. Frequency sweep to determine viscosity at varying frequency........................................... 2

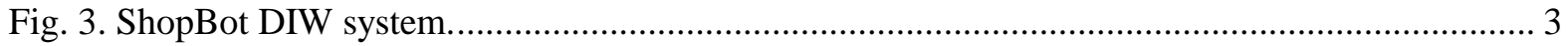

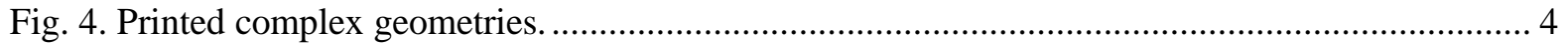




\section{ACKNOWLEDGEMENTS}

This CRADA NFE-16-06054 was conducted as a Technical Collaboration project within the Oak Ridge National Laboratory (ORNL) Manufacturing Demonstration Facility (MDF) sponsored by the US Department of Energy Advanced Manufacturing Office (CPS Agreement Number 24761).

Opportunities for MDF technical collaborations are listed in the announcement "Manufacturing Demonstration Facility Technology Collaborations for US Manufacturers in Advanced Manufacturing and Materials Technologies” posted at http://web.ornl.gov/sci/manufacturing/docs/FBO-ORNL-MDF2013-2.pdf. The goal of technical collaborations is to engage industry partners to participate in shortterm, collaborative projects within the Manufacturing Demonstration Facility (MDF) to assess applicability and of new energy efficient manufacturing technologies. Research sponsored by the U.S. Department of Energy, Office of Energy Efficiency and Renewable Energy, Advanced Manufacturing Office, under contract DE-AC05-00OR22725 with UT-Battelle, LLC. 



\begin{abstract}
ORNL worked with The DOW Chemical Company to validate the feasibility of 3D printing DOW's polyurethane (PU) materials using ORNL's equipment and know-how. This led to the development of the first directly-3D-printable PU material.
\end{abstract}

\title{
1. ADDITIVE MANUFACTURING OF POLYURETHANE MATERIALS
}

This Phase 1 technical collaboration project (MDF-TC-2016-080) was begun on February 1, 2016 and was completed on February 01, 2017. The collaboration partner The DOW Chemical Company (DOW) is a large business. ORNL successfully showed that DOW's polyurethane (PU) material is capable of being used as a 3D printing material for complex geometries.

\subsection{Background}

DOW is one of the industry leaders in polyurethane synthesis and manufacturing. DOW has developed polyurethane materials for use in 3D printing applications. This Phase 1 technical collaboration was necessary for DOW to utilize ORNL's additive manufacturing knowledge and equipment since the systems utilized by DOW were not designed for complex geometries. The team decided that using ORNL's thermoset printing system would allow the polyurethane to be printed into more complex and functional geometries and demonstrate the benefits of using the material. The demonstration of successfully printing complex geometries, as well as, mechanically characterizing printed parts qualifies the material for use as a 3D printable material for DOW.

\section{$1.2 \quad$ Technical Results}

Three tasks were laid out for this project. Task 1: Rheological characterization of extrudable PU polymers, Task 2: Printability tests with PU polymers, and Task 3: Mechanical characterization of printed parts. Tasks one and three were performed by DOW and task two was performed by ORNL.

\subsubsection{Rheological Characterization}

Rheological properties were measured by a parallel plate TA Instruments AR2000ex rheometer. Two different rheology tests were performed, a stress sweep (Figure 1) and a frequency sweep (Figure 2). The stress sweep was used to determine the linear viscoelastic region of the polymer. The frequency sweep was used to determine the viscosity and modulus for the selected polyurethane material. These tests showed the expected behavior of the polymer during and after extrusion which are within range of the required properties for printable materials. The material shows shear-thinning behavior that is typically necessary for successful 3-D printing. High zero shear viscosity of reactive polymers is required so that printed structures retain their shape after they exit the nozzle and before reaction takes place. At the same time, the viscosity must be low enough at shear rates observed within the nozzle to allow desired rates of flow at acceptable pressures within the system. 


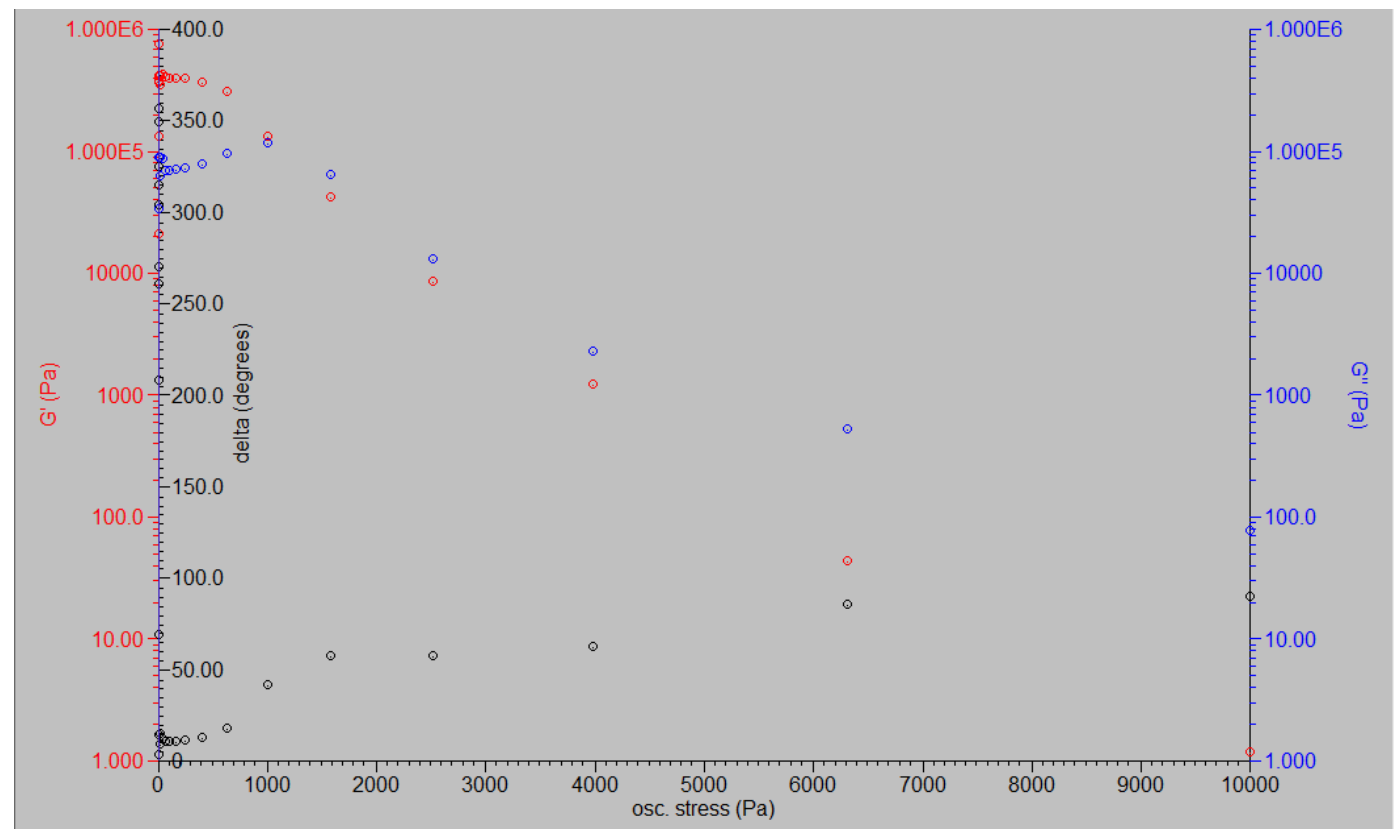

Fig. 1. Stress sweep to find the linear viscoelastic region.

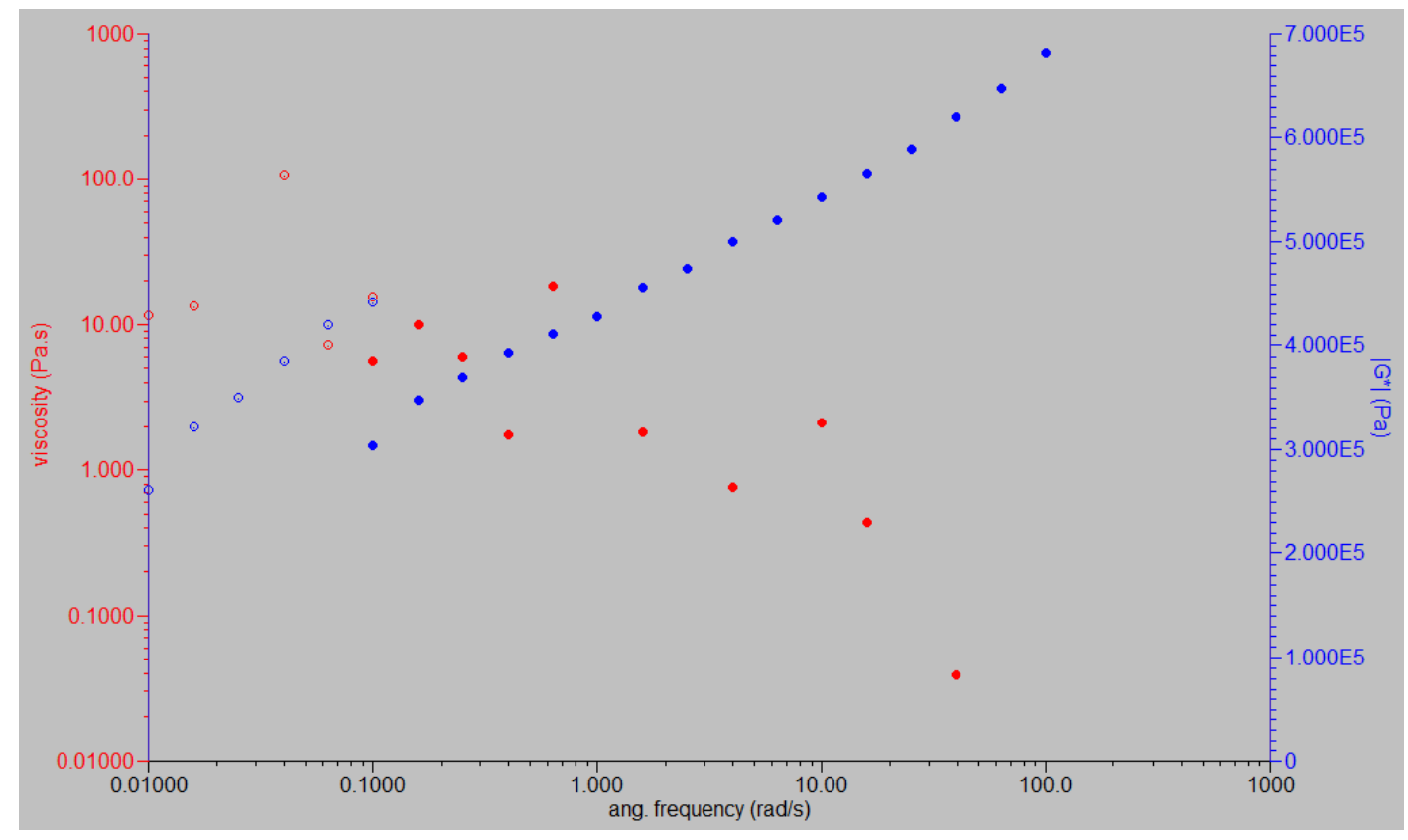

Fig. 2. Frequency sweep to determine viscosity at varying frequency.

\subsubsection{Printability Tests}

ORNL was initially provided a table of parameters for 3D printing DOW's moisture activated polyurethane system. These values were corroborated and confirmed at ORNL using the ShopBot thermoset printing system (Figure 3). The ShopBot system utilizes the same Nordson EFD extrusion system as DOW used for internal preliminary testing of PU printability. In these systems air pressure is used to push a plunger that extrudes material out of a syringe. The extruder is mounted on a ShopBot desktop Computer Numerically Controlled (CNC) router thus creating a 3D printer. 


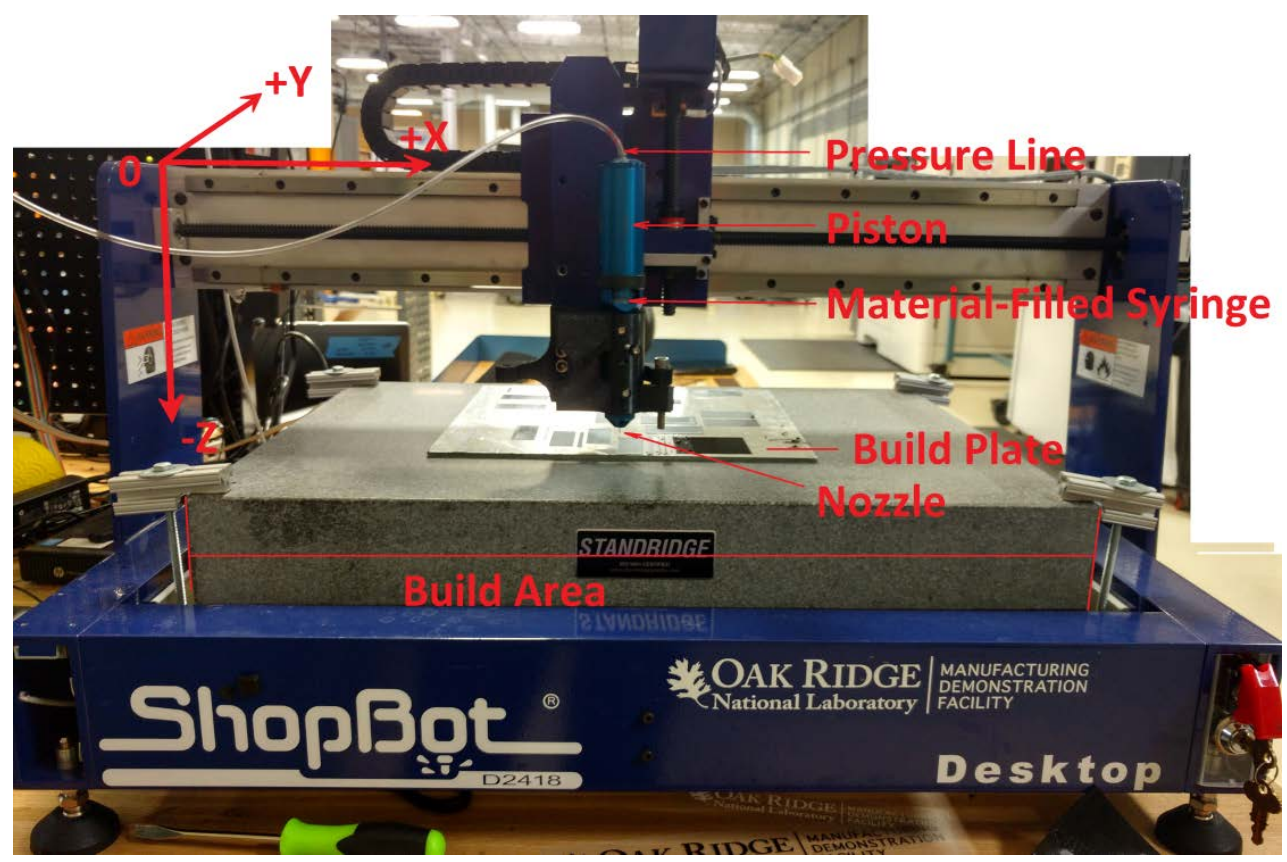

Fig. 3. ShopBot DIW system.

The smallest achievable extrusion diameter with repeatability was $0.2 \mathrm{~mm}$ bead width and $0.1 \mathrm{~mm}$ layer height. Thus the minimum feature size on a part printed with this PU material would have to be at least 200 microns in $\mathrm{X}$ and $\mathrm{Y}$ and 100 microns in $\mathrm{Z}$. The maximum build height is a function of the aspect ratio for the given geometry. The geometrical feature must have a height that is no bigger than three times the length of the smallest cross section measurement of the geometry in the X-Y plane. If the height is greater than this, the previously printed layers will begin to sway with the motion of the extruder as it deposits material. While slightly bigger aspect ratios can be achieved with fine tuning, remaining at or below this aspect ratio will give repeated good quality features. This holds true for solid objects being printed. When printing single bead width cellular structures the z height is only limited by material quantity in the syringe and consistency. Figure 4 shows some of the complex geometries printed at ORNL. 


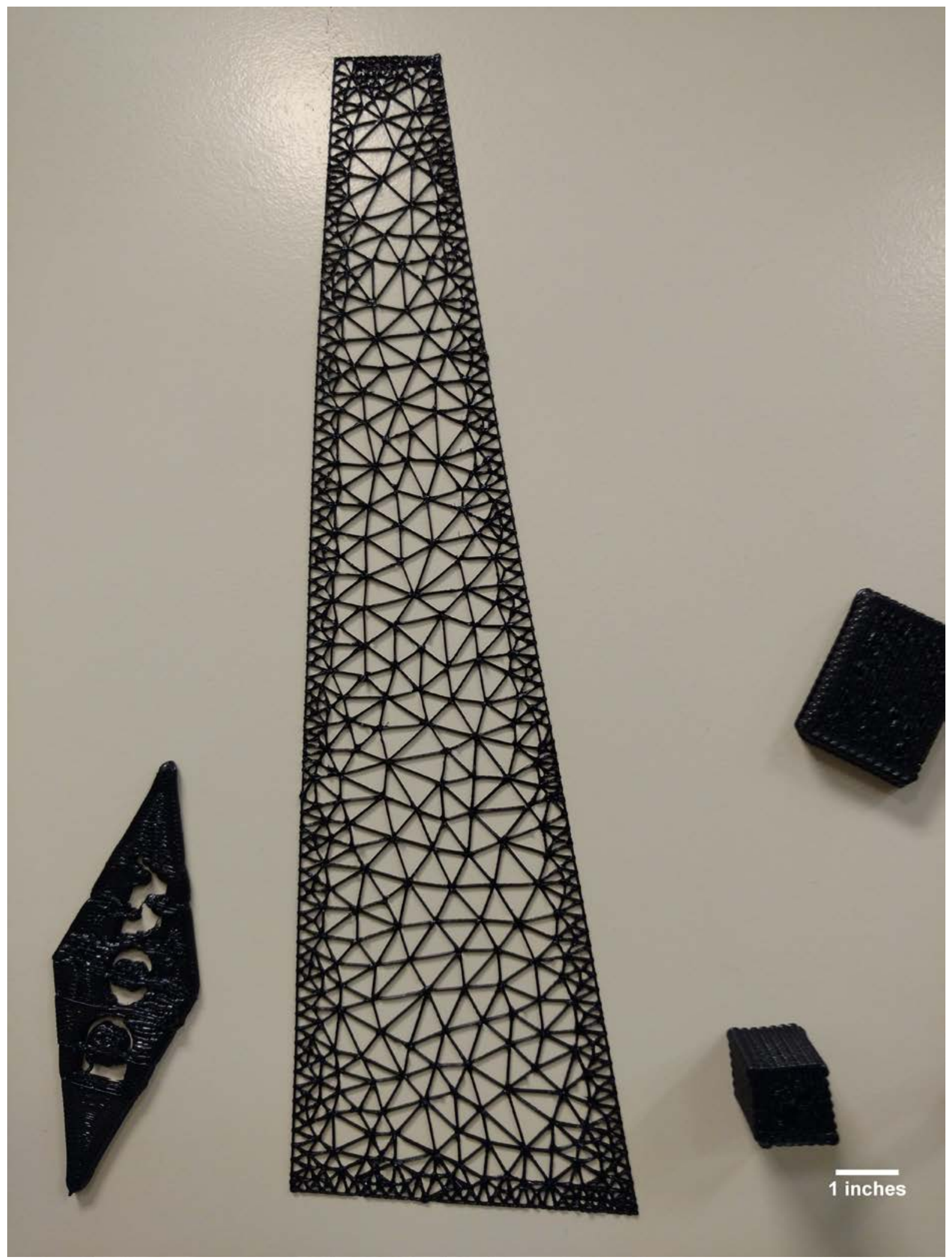

Fig. 4. Printed complex geometries. 


\subsubsection{Mechanical Testing}

Mechanical testing was performed on four different printed shapes: single layer dense rectangle 5 $\mathrm{cm}$ (in printed direction) x $2 \mathrm{~cm}$ (1), single layer dense rectangle $2 \mathrm{~cm}$ (in printed direction) x $5 \mathrm{~cm}$ (2), $5 \mathrm{~cm}$ (tall) single bead-walled hollow square (3), and 4 layer 0-90 dense $5 \mathrm{~cm}$. To maintain consistency, the same print parameters were across all the samples (Table 1.). Samples were printed oversized and cut to shape allowing multiple tests specimens from single prints.

Table 1. Mechanical testing printing parameters

\begin{tabular}{|c|c|c|c|c|c|}
\hline $\begin{array}{c}\text { Speed } \\
(\mathrm{mm} / \mathrm{min})\end{array}$ & $\Delta \mathrm{Y}(\mathrm{mm})$ & $\begin{array}{c}\text { Line } \\
\text { Width }(\mu \mathrm{m})\end{array}$ & $\begin{array}{c}\text { Layer } \\
\text { Height }(\mathrm{mm})\end{array}$ & PSI & $\begin{array}{c}\text { Nozzle } \\
\text { Size }(\mu \mathrm{m})\end{array}$ \\
\hline 1000 & 0.5 & 560 & 0.5 & 168 & 680 \\
\hline
\end{tabular}

Samples 1, 2, and 3 were cut to shape and analyzed using a TA Instruments texture analyzer with a pull speed of $25 \mathrm{~mm} / \mathrm{min}$. Samples 1 and 2 show the mechanical properties in the filament direction and perpendicular to the filament direction. Sample 3 tests the material in the z-direction. Sample 4 required an Instron Force analyzer due to the sample thickness, but the $25 \mathrm{~mm} / \mathrm{min}$ testing speed was maintained. Sample 4 is representative of the materials properties for dense printed parts in the $x-y$ plane. Table 2 shows a summary of the mechanical results for the printed polyurethane material.

Table 2. Mechanical testing results

\begin{tabular}{|c|c|r|r|r|r|r|}
\hline Sample & $\begin{array}{l}\text { Strength } \\
\text { (MPA) }\end{array}$ & Std. & $\begin{array}{l}\text { Elongation } \\
\text { (\%) }\end{array}$ & \multicolumn{1}{|c|}{ Std. } & $\begin{array}{l}\text { Modulus } \\
\text { (MPA) }\end{array}$ & Std. \\
\hline 1 & 5.99 & 0.32 & 1138.5 & 87.7 & 0.53 & 0.04 \\
\hline 2 & 5.30 & 0.24 & 1083.8 & 215.9 & 0.5 & 0.08 \\
\hline 3 & 2.08 & 0.3 & 294.2 & 13.6 & 0.71 & 0.12 \\
\hline 4 & 6.44 & 0.1 & 1010.2 & 94.9 & 0.64 & 0.07 \\
\hline
\end{tabular}

The testing results from samples 1 and 2 show almost isotropic material properties regardless of the print path in the $x-y$ plane. Lower strength, elongation, and modulus values for sample 3 printed in the z-direction shows that there is still a large difference between mechanical properties in the $\mathrm{x}-\mathrm{y}$ directions and the $\mathrm{z}$ direction. This lower strength in the $\mathrm{z}$-direction is common for plastic 3D printed materials. Sample 4 shows improved properties over 1 and 2 in modulus and strength.

\subsection{Impacts}

This project demonstrated a new material for 3D printing with promising results. It fills the void of elastomeric polymers in plastic 3D printing. The material can also be formulated to have specific properties for a given application. The process for printing this material also requires no energy input in the form of heat, unlike other plastic 3D printing processes, thus lowering the energy consumption. It also eliminates problems seen in fused deposition modeling such as thermal shrinkage and residual stresses. At the current time extrusion based systems for resins are not readily available on the market, but with continual growth of additive manufacturing DOW could offer this material to consumers for applications requiring elastomeric materials with high mechanical durability.

\subsection{Conclusions}

The goals for this project were met with success. Leveraging DOW's capabilities in polyurethane 
synthesis and ORNL's 3D printing equipment and know-how has led to the first directly printable polyurethane material. Mechanical testing shows promising results with DOW also being able to tailor these properties to a given application.

The next steps for advancing this technology would be to overcome the issues with aspect in tall slender objects. This can be done by moving to a two-part material that has a faster curing time. If the previously printed layers hardened, then the stability of the structure would increase and allow for taller fully dense geometries to be printed. Development of commercially available equipment that could utilize this material in larger quantities also would drive this technology forward. 


\section{THE DOW CHEMICAL COMPANY BACKGROUND}

Dow combines the power of science and technology to passionately innovate what is essential to human progress. The Company is driving innovations that extract value from the intersection of chemical, physical and biological sciences to help address many of the world's most challenging problems such as the need for clean water, clean energy generation and conservation, and increasing agricultural productivity. Dow's integrated, market-driven, industry-leading portfolio of specialty chemical, advanced materials, agrosciences and plastics businesses delivers a broad range of technology-based products and solutions. 